\title{
Ethnicity and the risk of late-pregnancy stillbirth
}

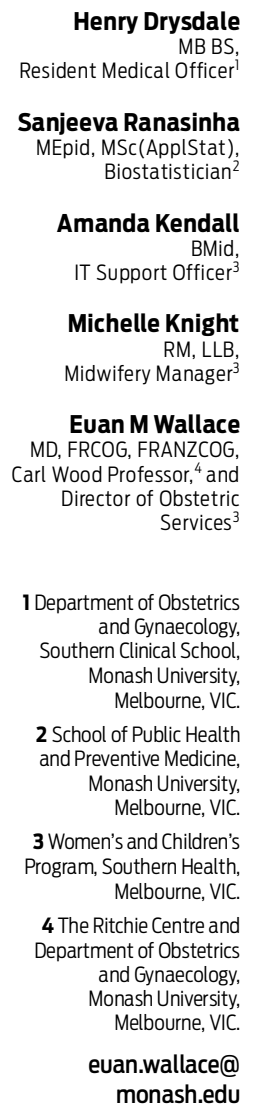

MJA 2012; 197: 278-281 doi: 10.5694/mjal2.10125

Editorial p 256 ustralia has among the world's lowest maternal and perinatal mortality rates, ${ }^{1}$ with the latter more than halving over the past 40 years. ${ }^{2,3}$ However, as in other highincome countries, a decline in neonatal rather than fetal deaths has mainly contributed to falling rates, leading to calls for more attention to preventing stillbirth. ${ }^{4-7}$ Identified maternal risk factors for stillbirth, such as obesity, advanced age, social deprivation, smoking, primiparity, pre-existing diabetes, and hypertension, ${ }^{4,7-10}$ may provide a foundation for intervention strategies. ${ }^{6}$ A risk factor that has received less attention is maternal ethnicity. One in four Australian births is to a woman who was born overseas. ${ }^{3}$ The risk of these women having a stillbirth is $13 \%$ higher than for Australian-born women. ${ }^{3}$

The influence of migration on pregnancy outcomes has been reported elsewhere. ${ }^{11,12}$ Its impact on perinatal mortality is influenced by many confounding factors, including the reason for migration (eg, refugees from war, elective skilled migration), the country of origin and destination, language barriers and access to health care. A consistent finding is that women of South Asian origin have higher rates of perinatal loss than other women. ${ }^{11}$ In 1983, the risk of stillbirth in women giving birth in London was 60\% higher for women born in the Indian subcontinent than for those born in the United Kingdom. ${ }^{13}$ Recent studies from the UK and the Netherlands showed that women of South Asian origin had an $80 \%$ higher risk of stillbirth than white women. ${ }^{14,15}$

Whether Asian women living in Australia have a higher risk of stillbirth than other women has not been reported. As migration to Australia from the Indian subcontinent has trebled over the past 10 years $^{16}$ and $10 \%$ of women giving birth in Australia today were born in

\section{Abstract \\ Objective: To determine if maternal country of birth is associated with the risk} of antepartum stillbirth in late pregnancy.

Design, setting and participants: Retrospective cross-sectional study of all singleton births at 37-42 weeks' gestation, excluding those with congenital abnormalities and intrapartum stillbirths, between 1 June 2001 and 31 May 2011 at Southern Health, a large metropolitan maternity service in Melbourne, Australia.

Main outcome measure: Rate of late-pregnancy antepartum stillbirth, analysed by maternal country of birth.

Results: Among 44326 births, there was a significant difference in the stillbirth rate by maternal country of birth $(P<0.001)$. The rate of stillbirth per 1000 births was 1.48 among Australian-born women, 3.55 among South Asian-born women and 1.06 among South-East-East Asian-born women. Women born in South Asia were $2.4(95 \% \mathrm{Cl}, 1.4-4.0)$ times more likely to have a latepregnancy stillbirth than women born in Australia $(P<0.001)$. There was no significant difference between women born in Australia and women born in South-East-East Asia $(P=0.34)$. Adjusting for potential confounding factors, South Asian maternal birth remained an independent risk factor for stillbirth (adjusted odds ratio, 2.5; 95\% Cl, 1.3-5.1; $P=0.009$ ).

Conclusion: Women born in South Asia have an increased risk of antepartum stillbirth in late pregnancy, compared with other women. This observation may have implications for the delivery of pregnancy care in Australia.

Asia, $^{3}$ we aimed to compare rates of late-pregnancy stillbirth in Asian-born and Australian-born women attending our maternity service.

\section{Methods}

We retrospectively analysed birth outcomes for all women with a singleton pregnancy giving birth to a baby without a congenital abnormality at 37-42 weeks' gestation at three metropolitan public hospitals (Monash Medical Centre, Dandenong Hospital, and Casey Hospital) in Southern Health between 1 June 2001 and 31 May 2011. We limited our analyses to latepregnancy births to avoid confounding effects of ethnicity and preterm birth $^{17}$ on stillbirth, and to exclude intrapartum losses, as the causes and risk factors of antepartum and intrapartum stillbirths differ. ${ }^{8}$

Data were extracted from the Birthing Outcomes System (BOS), an electronic database recording all births at $\geqslant 20$ weeks' gestation. For each birth, whether liveborn or stillborn, 46 data items are entered into the BOS by the attending midwife, with routine data validation. About half of all women giving birth at Southern Health during the study period were born overseas, in 178 countries. As our primary intent was to assess stillbirth risks in Asian women, we classified women into four regional groups according to their country of birth, as defined by the United Nations: ${ }^{18}$ Australia, South Asia, East Asia and South-East Asia (Box 1). We excluded all other women from our analyses.

Statistical analyses were undertaken using Stata version 11 (StataCorp). Continuous data were assessed for normality and are expressed as means and standard deviations. Categorical data are expressed as counts and proportions. We used analysis of variance to compare parametric continuous variables and the $\chi^{2}$ test for categorical variables. In addition to maternal country of birth, maternal and obstetric variables relevant to stillbirth ${ }^{4,6,7,19}$ 
were included in logistic regression analyses: maternal age, parity, body mass index (BMI; data only available from January 2007 onwards), smoking during pregnancy, previous caesarean section, pre-pregnancy diabetes, gestational diabetes, renal disease, thyroid disease, hypertension, gestation at birth, spontaneous prelabour rupture of membranes, and birthweight. Univariable and multivariable logistic regression analyses generated crude and adjusted odds ratios (ORs) for the independent variables. To derive the most parsimonious model, we included the covariates that were significant at the univariable level in the multivariable logistic regression model. We used the likelihood ratio test, Akaike and Bayesian information criteria, and area under the curve statistics to select the final model.

\section{Results}

During the 10-year period, there were 44326 singleton births of babies without known congenital abnormalities at 37-42 weeks' gestation to women born in the regions of interest. Of these births, 28380 (64.0\%) were to Australian-born women, 6471 (14.6\%) to South Asian-born women, $7407(16.7 \%)$ to South-East Asianborn women, and 2068 (4.7\%) to East Asian-born women. There were 75 antepartum stillbirths (1.69 per 1000 births): 42 to Australian-born women, 23 to South Asian-born women, eight to South-East Asian-born women, and two to East Asian-born women. As there was no significant difference in the stillbirth rate between SouthEast Asian-born and East Asian-born women $\left(1.08 \mathrm{v} 0.97\right.$ per $1000 ; \chi^{2}=$ $0.02, \mathrm{df}=1, P=0.89)$, these groups were combined into a South-EastEast Asian-born group for subsequent analyses, accounting for 9475 births (21.4\%) and 10 stillbirths.

There was a statistically significant difference in the stillbirth rate between Australian-born, South Asian-born, and South-East-East Asian-born women $(1.48,3.55$ and 1.06 per 1000 , respectively; $\chi^{2}=16.24$, $\mathrm{df}=2, P<0.001)$. South Asian-born women had a stillbirth rate 2.4 times (95\% CI, 1.4-4.0) higher than that of Australian-born women $\left(\chi^{2}=12.12\right.$, $\mathrm{df}=1, P<0.001)$ and 3.4 times $(95 \%$ CI, 1.6-7.1) higher than that of SouthEast-East Asian-born women $\left(\chi^{2}=\right.$ 11.65, $\mathrm{df}=1, P<0.001)$. There was no significant difference in the stillbirth rates between Australian-born and South-East-East Asian-born women $\left(\chi^{2}=0.93, \mathrm{df}=1, P=0.34\right)$. The relative risk of stillbirth in South Asian-born women compared with Australianborn women increased progressively with gestation: 1.09 (95\% CI, 0.30-

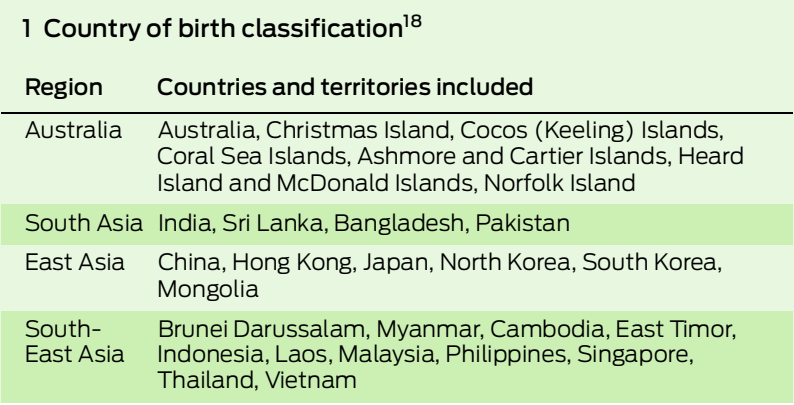

3.93; $P=0.89)$ at 37 weeks, $1.55(95 \%$ CI, $0.48-4.97 ; P=0.45)$ at 38 weeks, $3.08(95 \% \mathrm{CI}, 1.04-9.21 ; P=0.04)$ at 39 weeks, 3.12 (95\% CI, 1.02-9.58; $P=0.04)$ at 40 weeks, and $4.74(95 \%$ CI, $1.45-15.62 ; P=0.01)$ at 41 weeks (insufficient data at 42 weeks).

Compared with South Asian-born women, Australian-born women were more likely to have smoked during pregnancy $(\mathrm{OR}, 26.5 ; 95 \% \mathrm{CI}$, 20.6-34.3; $P<0.001)$, had a higher BMI, and were more likely to have hypertension (Box 2). In contrast, South Asian-born women were 2.8 times (95\% CI, 2.6-3.2; $P<0.001)$ more likely than Australian women to develop gestational diabetes. The rate of low-birthweight $(<2500 \mathrm{~g})$ babies was significantly higher among South Asian-born women than Australianborn women (Box 2).

Univariable logistic regression identified South Asian maternal

\begin{tabular}{|c|c|c|c|c|}
\hline & Australia & South Asia & South-East-East Asia & $P$ \\
\hline Number of women & 28380 & 6471 & 9475 & - \\
\hline \multicolumn{5}{|l|}{ Maternal characteristics } \\
\hline Mean (SD) age at birth & $29.7(5.6)$ & $29.6(4.4)$ & $30.5(5.1)$ & 0.001 \\
\hline Nulliparous & $12388(43.7 \%)$ & $3428(53.0 \%)$ & $4366(46.1 \%)$ & $<0.001$ \\
\hline Mean (SD) body mass index $(\mathrm{BMI})^{\dagger}$ & $26.8(6.3)$ & $24.3(4.1)$ & $22.4(3.4)$ & $<0.001$ \\
\hline Smoked during pregnancy & $6984(24.6 \%)$ & $60(0.9 \%)$ & $229(2.4 \%)$ & $<0.001$ \\
\hline Previous caesarean section & $3670(12.9 \%)$ & $925(14.3 \%)$ & $1008(10.6 \%)$ & $<0.001$ \\
\hline Pre-pregnancy diabetes & $270(1.0 \%)$ & $83(1.3 \%)$ & $49(0.5 \%)$ & $<0.001$ \\
\hline Gestational diabetes & $1147(4.0 \%)$ & $680(10.5 \%)$ & $1039(11.0 \%)$ & $<0.001$ \\
\hline Renal disease & $208(0.7 \%)$ & $28(0.4 \%)$ & $42(0.4 \%)$ & 0.001 \\
\hline Thyroid disease & $562(2.0 \%)$ & $225(3.5 \%)$ & $197(2.1 \%)$ & 0.001 \\
\hline Hypertensive disorder ${ }^{\ddagger}$ & $1931(6.8 \%)$ & $229(3.5 \%)$ & $257(2.7 \%)$ & $<0.001$ \\
\hline \multicolumn{5}{|l|}{ Pregnancy outcomes } \\
\hline Mean (SD) gestation at birth (weeks) & $39.5(1.2)$ & $39.3(1.2)$ & $39.4(1.1)$ & $<0.001$ \\
\hline $\begin{array}{l}\text { Mean }(95 \% \mathrm{Cl}) \text { gestation at birth (weeks) for births } \\
\text { with spontaneous onset of labour }\end{array}$ & $39.3(1.2)$ & $39.2(1.1)$ & $39.1(1.2)$ & $<0.001$ \\
\hline Spontaneous prelabour rupture of membranes & $2950(10.4 \%)$ & $779(12.0 \%)$ & $1011(10.7 \%)$ & $<0.001$ \\
\hline Mean (SD) birthweight (g) & $3463(497)$ & $3248(455)$ & $3288(497)$ & $<0.001$ \\
\hline Babies with birthweight $<2500 \mathrm{~g}$ & $672(2.4 \%)$ & $264(4.1 \%)$ & $225(2.4 \%)$ & $<0.001$ \\
\hline
\end{tabular}


birth, maternal age $\geqslant 40$ years, BMI $\geqslant 36 \mathrm{~kg} / \mathrm{m}^{2}$, pre-pregnancy diabetes and birthweight $<2500 \mathrm{~g}$ as independent risk factors for antepartum stillbirth (Box 3). Using the most parsimonious model from goodness-offit statistics, South Asian maternal birth, birthweight $<2500 \mathrm{~g}$ and BMI $\geqslant 36 \mathrm{~kg} / \mathrm{m}^{2}$ were the significant risk factors for stillbirth (Box 4).

\section{Discussion}

In this study, we found that South Asian-born women having a baby in a Victorian metropolitan maternity

\section{Prevalence and odds ratios (ORs) of risk factors for late-pregnancy antepartum stillbirth}

\begin{tabular}{|c|c|c|c|c|}
\hline Risk factor & No. of births & $\begin{array}{l}\text { No. of stillbirths } \\
\text { (rate per 1000) }\end{array}$ & Crude OR $(95 \% \mathrm{Cl})$ & $P$ \\
\hline \multicolumn{5}{|l|}{ Maternal region of birth } \\
\hline Australia* & 28380 & $42(1.48)$ & 1 & - \\
\hline South Asia & 6471 & $23(3.55)$ & $2.4(1.4-4.0)$ & $<0.001$ \\
\hline South-East-East Asia & 9475 & $10(1.06)$ & $0.7(0.4-1.4)$ & 0.34 \\
\hline \multicolumn{5}{|l|}{ Maternal age (years) } \\
\hline$<25 *$ & 7380 & $7(0.95)$ & 1 & - \\
\hline $25-29$ & 13786 & $27(1.96)$ & $2.1(0.9-4.7)$ & 0.09 \\
\hline $30-34$ & 14314 & $20(1.40)$ & $1.5(0.6-3.5)$ & 0.38 \\
\hline 35-39 & 7338 & $14(1.91)$ & $2.0(0.8-5.0)$ & 0.13 \\
\hline$\geqslant 40$ & 1508 & $7(4.64)$ & $5.0(1.7-14.0)$ & 0.003 \\
\hline \multicolumn{5}{|l|}{ Parity } \\
\hline Nulliparous* & 20182 & $40(1.98)$ & 1 & - \\
\hline$\geqslant 1$ & 24144 & $35(1.45)$ & $0.7(0.5-1.2)$ & 0.18 \\
\hline \multicolumn{5}{|l|}{ Body mass index $\left(\mathrm{kg} / \mathrm{m}^{2}\right)^{\dagger}$} \\
\hline$<19$ & 1038 & $3(2.89)$ & $2.5(0.6-6.7)$ & 0.26 \\
\hline 19-25.9* & 14450 & $21(1.45)$ & 1 & - \\
\hline $26-35.9$ & 8257 & $16(1.94)$ & $1.3(0.7-2.6)$ & 0.39 \\
\hline$\geqslant 36$ & 1581 & $6(3.80)$ & $2.6(1.1-6.4)$ & 0.03 \\
\hline \multicolumn{5}{|l|}{ Smoking during pregnancy } \\
\hline No* & 37053 & $61(1.65)$ & 1 & - \\
\hline Yes & 7273 & $13(1.79)$ & $1.1(0.6-2.2)$ & 0.79 \\
\hline \multicolumn{5}{|l|}{ Previous caesarean } \\
\hline No* & 38723 & $67(1.73)$ & 1 & - \\
\hline Yes & 5603 & $8(1.43)$ & $0.8(0.4-1.7)$ & 0.61 \\
\hline \multicolumn{5}{|l|}{ Pre-pregnancy diabetes } \\
\hline No* & 43924 & $72(1.64)$ & 1 & - \\
\hline Yes & 402 & $3(7.46)$ & $4.6(1.4-14.5)$ & 0.01 \\
\hline \multicolumn{5}{|l|}{ Gestational diabetes } \\
\hline No* & 41460 & $71(1.71)$ & 1 & - \\
\hline Yes & 2866 & $4(1.40)$ & $0.8(0.3-2.2)$ & 0.87 \\
\hline \multicolumn{5}{|l|}{ Renal disease } \\
\hline No* & 44048 & $75(1.70)$ & - & - \\
\hline Yes & 278 & $0(0)$ & - & - \\
\hline \multicolumn{5}{|l|}{ Thyroid disease } \\
\hline No* & 43342 & $71(1.64)$ & 1 & - \\
\hline Yes & 984 & $4(4.06)$ & $2.5(0.9-7.0)$ & 0.07 \\
\hline \multicolumn{5}{|l|}{ Hypertension } \\
\hline No* & 41914 & $70(1.67)$ & 1 & - \\
\hline Yes & 2412 & $5(2.07)$ & $1.3(0.5-3.1)$ & 0.64 \\
\hline \multicolumn{5}{|l|}{ Birthweight of baby } \\
\hline$<2500 \mathrm{~g}$ & 1161 & $12(10.34)$ & $7.4(3.9-13.8)$ & $<0.001$ \\
\hline $2500-4000 \mathrm{~g} *$ & 38509 & $54(1.40)$ & 1 & - \\
\hline$>4000 \mathrm{~g}$ & 4656 & $7(1.50)$ & $1.1(0.5-2.3)$ & 0.86 \\
\hline \multicolumn{5}{|c|}{ Spontaneous prelabour rupture of membranes } \\
\hline No* & 39589 & $70(1.77)$ & 1 & - \\
\hline Yes & 4737 & $5(1.06)$ & $0.6(0.3-1.4)$ & 0.26 \\
\hline
\end{tabular}

* Reference group. † BMI data only available from January 2007 onwards (25326 women).

service were more than twice as likely to have a late-pregnancy antepartum stillbirth than either Australian-born or South-East-East Asian-born women attending the same service. The established risk factors for stillbirth in Australia did not explain this increased risk. These results support observations in other Western populations that women of South Asian origin have a higher risk of stillbirth than other women. ${ }^{12-15,20}$ However, the reasons for this difference remain obscure.

Although it is a significant public health issue that some migrant women have significantly different pregnancy outcomes to non-migrant women, migration per se is not a risk factor for stillbirth. ${ }^{11,15,21}$ This is supported by our observation of similar stillbirth rates among South-EastEast Asian-born and Australian-born women. Further, the South Asian women with a higher stillbirth rate in a recent UK study were not migrants but UK-born, ${ }^{14}$ suggesting that the risk of stillbirth in South Asian women may relate to their ethnicity and not to migration.

We found differences between South Asian-born and Australianborn women with regard to several risk factors for stillbirth, but these differences did not explain the increased rate in South Asian-born women. This is important for two reasons. First, targeting modifiable risk factors such as smoking and obesity, ${ }^{7}$ while certainly important, would not be expected to afford the same returns in South Asian-born women as in Australian-born women. Second, the lack of relationship between South Asian origin and some of the established risk factors suggests that other mechanisms causing stillbirth are at play. The risk of stillbirth in late pregnancy has been found to increase earlier in South Asian women than in white women, ${ }^{14}$ leading to the suggestion that fetal surveillance or induction of labour should be considered at an earlier gestation in South Asian women. ${ }^{14,15}$ Our data confirm that the relative risk of stillbirth in South Asian-born women increases with advancing gestation, supporting consideration of an ethnicity-based intervention policy. 
Another feature of the South Asian-born women in our study is that, on average, they had smaller babies than other women, and a higher rate of low-birthweight $(<2500 \mathrm{~g})$ babies. Small size at birth is a major risk factor for stillbirth. ${ }^{7,9,21}$ We found a low birthweight was associated with a sevenfold increased risk of stillbirth, although there were no differences in the rates of stillbirth among low-birthweight babies between the three groups of women. Nonetheless, that South Asian-born women had nearly twice the rate of low-birthweight babies than other women merits further investigation.

Others have shown that differences in birthweight related to maternal factors such as race ${ }^{22}$ or stature ${ }^{23}$ probably do not simply reflect normal physiology but are pathological - the smaller babies born to United Statesborn black women or women of short stature, compared with the overall population, have increased risks of both stillbirth and neonatal death. This is important because the use of fetal growth charts customised by maternal characteristics, including ethnicity, has recently found increasing favour in clinical practice in the expectation that they will improve the detection of fetal growth restriction. ${ }^{24}$ However, such charts are based on the premise that differences in birthweight related to maternal attributes are physiological, not pathological. This may well be false. ${ }^{21,23,25}$ Indeed, if applied to a South Asian population, customised growth charts may impair the detection of fetal growth restriction and so increase the risk of stillbirth. ${ }^{14,22,25}$ The impact of the routine use of such charts on perinatal outcomes needs careful evaluation before they can be recommended for routine care. ${ }^{7}$

Our study has some limitations. Our dataset records maternal country of birth rather than ethnicity per se. Given that an increased risk of stillbirth has also been observed in UKborn women of South Asian descent, ${ }^{14}$ we believe that Australian datasets should collect information on both maternal country of birth and ethnicity, to afford the ability to tease apart their effects on pregnancy outcomes. Assessing ethnicity (in addition to country of birth) as a risk factor for stillbirth will become more impor- tant as the number of Australian-born women of South Asian descent increases, as has occurred in the UK. ${ }^{13,14}$ We urge that consideration be given to revisiting how national data regarding ethnicity and pregnancy outcome are collected.

We were also unable to adjust for previous pregnancy complications, such as preterm birth, stillbirth, or growth restriction, or for socioeconomic status or access to care. Social disadvantage and inadequate care are recognised risk factors for stillbirth. ${ }^{9,13,21}$ However, as with European studies, ${ }^{13-15,20}$ the women in our study had free access to maternity care. Although we were unable to measure uptake of pregnancy care, lack of access to appropriate care is not a likely explanation for the observed differences. Future research should address socioeconomic characteristics and appropriate use of antenatal care as possible contributors to stillbirth risk across different ethnic groups. Last, we were unable to examine the attributable causes of each stillbirth to explore whether mechanisms of loss differed between ethnic groups. This would be worthwhile.

In summary, we found that South Asian-born women had a significantly higher risk of late-pregnancy antepartum stillbirth than other women. This increased risk was not attributable to known risk factors for stillbirth, suggesting other causative mechanisms. In a racially diverse country like Australia, we believe that uncovering those mechanisms will be necessary to secure improvements in perinatal outcomes for all women.

Acknowledgements: This work was supported by funding from the Victorian Government's Operational Infrastructure Support Program.

\section{Competing interests: No relevant disclosures.}

Received 19 Jan 2012, accepted 24 Jul 2012.

1 World Health Organization. World health statistics 2011. Geneva: WHO Publications, 2011. http://www.who.int/gho/publications/world_ health_statistics/EN_WHS2011_Full.pdf (accessed Dec 2011)

2 Day P, SullivanEA, Ford J, Lancaster P. Australia's mothers and babies 1997. Sydney: Australian Institute of Health and Welfare, 1999. (AlHW Cat. No. PER 12; Perinatal Statistics Series No. 9.) http:// www.preru.unsw.edu.au/PRERUWeb.nsf/ resources/PS_6_10/\$file/ps9.pdf (accessed Dec 2011).

3 Li Z, McNally L, Hilder L, Sullivan EA. Australia's mothers and babies 2009. Canberra: Australian Institute of Health and Welfare, 2011. (AlHW Cat. No. PER 52; Perinatal Statistics Series No. 25.) http:// aihw.gov.au/publication-detail/?id= 10737420870\&tab=2 (accessed Dec 2011).
4 Adjusted odds ratios (ORs) of risk factors for latepregnancy antepartum stillbirth

\begin{tabular}{lcc} 
Risk factor & Adjusted OR $(95 \% \mathrm{Cl})$ & $P$ \\
\hline $\begin{array}{l}\text { Maternal region of birth } \\
\quad \text { Australia* }\end{array}$ & 1 & \\
$\quad$ South Asia & $2.5(1.3-5.1)$ & 0.009 \\
$\quad$ South-East-East Asia & $1.3(0.6-3.2)$ & 0.51 \\
Birthweight & $7.4(3.2-19.0)$ & $<0.001$ \\
$<2500 \mathrm{~g}$ & 1 & \\
$2500-4000 \mathrm{~g} *$ & $1.3(0.5-3.3)$ & 0.63 \\
$>4000 \mathrm{~g}$ & $1.8(0.5-6.2)$ & 0.36 \\
Body mass index $\left(\mathrm{kg} / \mathrm{m}^{2}\right)$ & 1 & 0.29 \\
$<19$ & $1.4(0.7-2.9)$ & 0.007 \\
\hline $\begin{array}{l}19-25.9 * \\
26-35.9\end{array}$ & $3.8(1.4-10.2)$ & \\
\hline 236 & &
\end{tabular}

4 Smith GCS, Fretts RC. Stillbirth. Lancet 2007; 370: 1715-1725.

5 Woods R. Long-term trends in fetal mortality: implications for developing countries. Bull World Health Organ 2008; 86: 460-466.

6 Flenady V, Middleton P, Smith GC, et al. Stillbirths: the way forward in high-income countries. Lancet 2011; 377: 1703-1717.

7 Flenady V, Koopmans L, Middleton P, et al. Major risk factors for stillbirth in high-income countries: a systematic review and meta-analysis. Lancet 2011; 377: $1331-1340$.

8 Lawn JE, Blencowe H, Pattinson R, et al. Stillbirths: Where? When? Why? How to make the data count? Lancet 2011; 377: 1448-1463.

9 Mohsin M, Bauman AE, Jalaludin B. The inuence of antenatal and maternal factors on stillbirths and neonatal deaths in New South Wales, Australia. J Biosoc Sci 2006; 38: 643-657.

10 Huang L, Sauve R, Birkett N, et al. Maternal age and risk of stillbirth: a systematic review. CMAJ 2008; 178: 165-172.

11 Gagnon AJ, Zimbeck M, Zeitlin J, et al. Migration to western industrialised countries and perinatal health: a systematic review. Soc Sci Med 2009; 69: 934-946.

12 Gissler M, Alexander S, MacFarlane A, et al. Stillbirths and infant deaths among migrants in industrialized countries. Acta Obstet Gynecol Scand 2009; 88: 134-148.

13 Parsons L, Duley L, Alberman E. Socio-economic and ethnic factors in stillbirth and neonatal mortality in the NE Thames Regional Health Authority (NETRHA) 1983. Br J Obstet Gynaecol 1990; 97: 237-244.

14 Balchin I, Whittaker JC, Patel RR, et al. Racial variation in the association between gestational age and perinatal mortality: prospective study. BMJ 2007; 334: 833. doi: 10.1136/bmj.39132.482025.80.

15 Ravelli ACJ, Tromp M, Eskes M, et al. Ethnic differences in stillbirth and early neonatal mortality in The Netherlands. J Epidemiol Community Health 2011; 65: 696-701.

16 Australian Bureau of Statistics. Migration, Australia, 2009-10. Canberra: ABS, 2011. http://www.ausstats.abs.gov.au/Ausstats/subscriber.nsf/0/ CAC6E05106F66A13CA2578B000119F19/\$File/34120_2009-10.pdf (accessed Dec 2011).

17 MacDorman MF. Race and ethnic disparities in fetal mortality, preterm birth, and infant mortality in the United States: an overview. Semin Perinatol 2011; 35 : 200-208.

18 United Nations Statistics Division. Composition of macro geographical (continental) regions, geographic sub-regions, and selected economic and other groupings. New York: UN, 2011. http://unstats.un.org/unsd/methods/m49/m49regin.htm (accessed Dec 2011).

19 Getahun D, Ananth CV, Kinzler WL. Risk factors for antepartum and intrapartum stillbirth: a population-based study. Am J Obstet Gynecol 2007; 196: 499-507.

20 Raleigh VS, Botting B, Balarajan R. Perinatal and postneonatal mortality in England and Wales among immigrants from the Indian subcontinent. Indian J Pediatr 1990; 57: 551-562.

21 Rowland Hogue CJ, Silver RM. Racial and ethnic disparities in United States: stillbirth rates: trends, risk factors, and research needs. Semin Perinatol 2011; 35: 221-233.

22 Kramer MS, Ananth CV, Platt RW, Joseph KS. US Black vs White disparities in foetal growth: physiological or pathological? Int J Epidemiol 2006; 35: 1187-1195.

23 Zhang X, Mumford SL, Cnattingius S, et al. Reduced birthweight in short or primiparous mothers: physiological or pathological? BJOG 2010; 117: 1248-1254.

24 Royal College of Obstetricians and Gynaecologists. The investigation and management of the small-for-gestational-age fetus. Guideline No. 31. London: RCOG, 2002.

25 Hutcheon JA, Zhang X, Platt RW, et al. The case against customised birthweight standards. Paediatr Perinat Epidemiol 2011; 25: 11-16. 